\title{
Effect of Duration of Calot's Triangle Dissection on the Definition of Difficult Cholecystectomy
}

\author{
Emin Köse (1) \\ Department of General Surgery, University of Health Sciences Okmeydanı Training and Research Hospital, İstanbul, Turkey
}

Cite this article as: Köse E. Effect of Duration of Calot's Triangle Dissection on the Definition of Difficult Cholecystectomy. JAREM 2019; 9(1): 22-6.

\begin{abstract}
Objective: The aim of the study was to investigate the effect of Calot's triangle dissection time on convert to open elective laparoscopic cholecystectomy to open cholecystectomy, prolonged operation time ( $\geq 120 \mathrm{~min})$, and prediction of the difficulty associated with complications development.

Methods: A retrospective analysis was performed in patients who were diagnosed with cholelithiasis and planned for laparoscopic cholecystectomy between March 2015 and November 2016. Demographic and clinical data (previous operation history, acute cholecystitis, a history of cholangitis and pancreatitis, history of endoscopic retrograde cholangiopancreatography, and Calot's dissection duration and total operation time) were collected from 300 patients involved in the study. A total operation time lasting 120 minutes and longer, convert to open cholecystectomy from the laparoscopic technique, and intraoperative complication related with cholecystectomy (biliary injury, uncontrolled bleeding) were chosen as difficult cholecystectomy and named as Group 1. All other patients out of these findings were put in as Group 2. The factors that caused difficult cholecystectomy were analyzed statistically.

Results: The mean age of patients was $50.6 \pm 14$ years; 203 (68\%) were female and 97 (32\%) were male. A total of 25 patients (8\%) were considered to have difficult cholecystectomy (Group 1). There was a statistically significant difference between the groups in terms of gender ( $p=0.002$ ), acute cholecystitis $(p=0.009)$, and acute cholangitis history $(p=0.009)$. Calot's dissection duration and operation time were significantly longer in Group 1 ( $p=0.0001$ and $p=0.0001$, respectively). Calot's dissection optimum time was defined as 15 minutes $(72 \%$ sensitivity and $84.7 \%$ specificity) in patients who were considered to have difficult cholecystectomy. There was a significant correlation between the duration of Calot's dissection time that was longer than 15 minutes and the occurrence of difficult cholecystectomy $(p=0.0001)$.

Conclusion: The failure to complete Calot's triangle within a specified time during elective cholecystectomy procedures can be considered as a difficult cholecystectomy criterion.
\end{abstract}

Keywords: Calot's triangle dissection, difficult cholecystectomy, laparoscopic cholecystectomy, open cholecystectomy

\section{INTRODUCTION}

Laparoscopic cholecystectomy (LC) is currently considered as the gold standard for the surgical treatment of symptomatic cholelithiasis and benign gallbladder pathologies $(1,2)$. Significant advantages of LC are less postoperative pain, shorter hospital stay, early return to normal activity, and cosmetic advantage when compared with open cholecystectomy (3-5). One of the most important causes of morbidity in LC is that it cannot be completed laparoscopically due to technical difficulties or intraoperative complications (1). The most important reasons convert to open procedure are insufficient anatomy (50\%), bleeding (14\%), choledocholithiasis suspicion (11\%), suspected bile duct injury (8\%), and other reasons (16\%) (6). The possibility of laparoscopic completion of cholecystectomy will have many advantages in the prediction of complications that may occur during which has many advantages $(3,7)$. In difficult cholecystectomy cases, the involvement of an experienced surgical team at the initial stage of surgery can be preventive for situations that may increase morbidity, such as transition to the margin, biliary tract injury, and major bleeding. Many advantages of preoperative or preoperative surgery can be predicted before any complications occur. In previous studies on this subject, it has been shown that different factors are related convert to open procedure (6, 8-10). Considering these studies, it is noteworthy that there are still no generally accepted objective criteria for the determination of difficult cholecystectomy.

The term difficult or very difficult cholecystectomy is an issue used in the literature, but uncertainty regarding its identification exists. As the prolongation of anesthesia and duration of surgery are closely related to the morbidity in patients, different definitions regarding the duration of surgery are found. While an experienced surgeon completes cholecystectomy at $>50 \%$ of

ORCID ID of the author: E.K. 0000-0002-0888-2576. 
his standard time, which is considered as a criterion for difficult cholecystectomy, the obtained values do not apply to other surgeons (4). The absence of complication development and transition to be performed is considered as an objective criteria for the definition of difficult cholecystectomy (11).

In previous studies, it is thought that the fact that Calot's triangle dissection is not anatomically revealed due to patient- or surgeon-related factors is associated with LC difficulty (8). Although the determination of a generally acceptable cut-off value may be technically challenging, the failure of the Calot's triangle dissection to be completed within a predetermined period may be an early predictor of $\mathrm{LC}$ with regard to both long operative time and complication development $(4,12,13)$. When Calot's dissection time is defined objectively and the effects on perioperative complications and outcomes are revealed, difficult cholecystectomy is a simple but an effective criterion.

The aim of the present study was to investigate the effect of LC during elective conditions on the time to transition, prolonged operation time (>120 min), and the development of complication and the difficulty via the effect of the time of dissection on the Calot's triangle.

\section{METHODS}

This was a retrospective study conducted on 392 consecutive patients who underwent elective LC with a diagnosis of cholelithiasis between March 2015 and November 2016. Patients with a diagnosis of preoperative acute cholecystitis were excluded from the study because they were thought to disrupt the homogeneity of the groups. Patients with simultaneous second biliary intervention $(n=16)$, open cholecystectomy on the initiative of the responsible surgeon $(n=66)$, chronic liver disease $(n=8)$, and intraoperative cholecystoduodenal fistula $(n=2)$ were also excluded. A total 300 patients were included in the study. The study was approved by the ethics committee of the hospital in accordance with the principles of the Declaration of Helsinki.

Demographic data, body mass index (BMI) $\left(\mathrm{kg} / \mathrm{m}^{2}\right)$, and clinical data (history of previous surgery, history of acute cholecystitis, cholangitis and pancreatitis, history of endoscopic retrograde cholangiopancreatography (ERCP), and total operation time with Calot's dissection time) were compiled retrospectively from the database.

\section{Surgical Technique}

All cholecystectomies included in the study were performed by a single hepatobiliary surgeon. LC was performed using 4 trocar techniques as a standard in all cases using a $10 \mathrm{~mm}$ trocar core hole using open Hasson technique; $12 \mathrm{~mm} \mathrm{Hg}$ pneumoperitoneum was created by $\mathrm{CO}_{2}$ gas. Then, $10 \mathrm{~mm}$ from the epigastric area, $2 \mathrm{~cm}$ inferior of the right subcostal line, $5 \mathrm{~mm}$ from the right anterior axillary line intersection, right transversal line of the right lateral of the right, and $5 \mathrm{~mm}$ trocar site were entered.

The time from initial trocar placement to suturing of the last trocar to the skin incision was recorded as the total operative time. With the initiation of cholecystoduodenal region dissection, the time to complete the dissection of the Calot's triangle and the cystic artery and channel to be clipped and cut was recorded as the "Calot's triangle dissection time."
Cholecystectomies with a total operative time of $\geq 120$ min which converted from laparoscopy to open operation and developed complications associated with cholecystectomy in the intraoperative period (biliary injury and uncontrollable bleeding) were defined as difficult cholecystectomy (Group 1). The reasons for the cases returned from laparoscopy were also stated. Open cholecystectomy was completed with the right subcostal incision in all patients and the separation of the gallbladder from the liver bed following cystic artery and duct ligation with the intervention to the cause of revision.

In the postoperative period, in case of a complication associated with cholecystectomy, this was not evaluated as a difficult cholecystectomy. A case of more than one difficult cholecystectomy criterion was also indicated. The remaining patients were classified as Group 2.

\section{Statistical Analysis}

Statistical analyses were performed using the Number Cruncher Statistical System (2007) and Power Analysis and Sample Size statistical programs (2008; UT, USA).

Variables with normal distribution were presented as mean \pm standard deviation, and variables with non-normal distribution were presented as median \pm standard deviation. Student's t-test was used for parametric variables, and chi-square test was used for complication analysis by gender. Multiple regression analysis was performed for dichotomized variables, such as exposures and complications, whereas linear regression analysis was performed for continuous variables, such as hospital stay and duration of surgery. The optimum threshold values were determined using the receiver operating characteristic (ROC) curve and the area under curve to estimate the difficulty of surgery with Calot's dissection time. The statistical results were expressed as odds ratio using the $95 \%$ confidence interval. A $p$ value of $\leq 0.05$ was considered as statistically significant.

\section{RESULTS}

The mean age of the patients was $50.6 \pm 14$ years. The study included 203 (68\%) female and 97 (32\%) male patients. Other demographic characteristics of the patients are shown in Table 1. A total of 25 (8\%) patients were classified as Group 1 (difficult cholecystectomy), and 275 (92\%) patients were classified as Group 2. Difficult cholecystectomy criteria and difficult cholecystectomy according to each criterion are shown in Table 2. The most common criterion for difficult cholecystectomy was laparoscopy (17 patients, 68\%), and the most common causes were adhesion (11 patients) and bleeding (6 patients). Intraoperative biliary complication development was not seen in the patient groups.

Although there was no difference between the groups with regard to age, BMI, previous surgery, and acute pancreatitis history ( $p>0.05$ for all), there was a statistically significant difference with regard to gender $(p=0.002)$, previous acute cholecystitis $(p=0.009)$, and history of acute cholangitis $(p=0.009)$ (Table 1). Acute cholecystitis and cholangitis attack and male gender were significantly higher in Group 1. The Calot's dissection time and duration of surgery were significantly longer in Group 1 $(p=0.0001$ and $p=0.0001$, respectively) (Table 3). ROC analysis was performed to determine the optimum duration of Calot's 
dissection in patients with difficult cholecystectomy, and this time was determined as $15 \mathrm{~min}$ with a sensitivity of $72 \%$ and specificity of $84.7 \%$. In the group of patients included in the study, $50 \%$ of the patients with a Calot's dissection duration of $\geq 15$ min were included in Group 1, whereas $90.4 \%$ of those $<15$ min were included in Group 2. There was a significant relationship between the occurrence of difficult cholecystectomy and the duration of dissection of the Calot's dissection for $>15$ min $(p=0.0001)$ (Table 4, Figure 1)

A total of 12 postoperative complications were observed in both groups. Of the 12 postoperative complications, Group 1 had 9 (36\%), and Group 2 had 3 (1.1\%), and the difference was statistically significant $(p=0.0001)$ (Table 5$)$. In Group 1, two patients were diagnosed with cystic stump leak; one patient was treated with ERCP, whereas the other patient was reoperated. In both groups, choledocholithiasis detected in the postoperative period was treated with ERCP.

In the multiple regression analysis performed with gender, history of acute cholecystitis episode, history of acute cholangitis attack, and the duration of Calot's dissection $>15$ min, it was found that the duration of Calot's dissection $>15$ min was significant in predicting difficult cholecystectomy ( $p=0.0001$ ) (Table 6).

Table 1. Clinical and demographic characteristics of the patients

\begin{tabular}{|c|c|c|c|c|}
\hline & & Grc & ups & \\
\hline & $\begin{array}{l}\text { Total, } \\
\text { n (\%) }\end{array}$ & $\begin{array}{l}\text { Group 1, } \\
\text { n (\%) }\end{array}$ & $\begin{array}{c}\text { Group 2, } \\
\text { n (\%) }\end{array}$ & $p$ \\
\hline$n(\%)$ & 300 & $25(8.3)$ & 275 (91.7) & \\
\hline Age (year) & $50.6 \pm 14$ & $52.4 \pm 12.7$ & $50.44 \pm 14.1$ & 0.512 \\
\hline Gender (F/M) & 203/97 & $15 / 10$ & $193 / 82$ & 0.002 \\
\hline BMI & $28.9 \pm 5.5$ & $29.7 \pm 5.4$ & $28.8 \pm 5.6$ & 0.427 \\
\hline Previous surgery & 14 & 3 & 11 & 0.101 \\
\hline $\begin{array}{l}\text { Acute cholecystitis } \\
\text { in the past }\end{array}$ & 98 & 14 & 84 & 0.009 \\
\hline $\begin{array}{l}\text { Acute cholangitis } \\
\text { in the past }\end{array}$ & 6 & 3 & 3 & 0.009 \\
\hline $\begin{array}{l}\text { Acute pancreatitis } \\
\text { in the past }\end{array}$ & 16 & 0 & 16 & 0.378 \\
\hline History of ERCP & 24 & 4 & 20 & 0.126 \\
\hline
\end{tabular}

Table 2. Difficult cholecystectomy criteria and patient numbers

\begin{tabular}{|l|c|c|}
\hline Indication & $\mathbf{n = 2 5 *}$ & \% \\
\hline Conversion & 17 & 68 \\
\hline Operating time $>120$ min & 12 & 48 \\
\hline Biliary injury & - & - \\
\hline Bleeding & 6 & 24 \\
\hline *More than one criterion in one patient & & \\
\hline
\end{tabular}

\section{DISCUSSION}

Laparoscopic cholecystectomy, first described by Muhe in 1985, is still used as the gold standard in the treatment of cholelithiasis $(1,2)$. Complication rates vary between $1.5 \%$ and $17 \%(14)$. The most common cause of the transition to the opening is the difficulty of dissection of the Calot's triangle that is usually due to severe inflammation and adhesion. Other causes include older age, male gender, severe cholecystitis, previous upper abdominal surgery, obesity, choledocholithiasis and related ERCP, severe cardiopulmonary disease, and high American Society of Anesthesiologists score $(6,15,16)$. When the studies performed are

\section{Table 3. Perioperative results between the groups}

\begin{tabular}{|l|c|c|c|c|} 
& $\begin{array}{c}\text { Total, } \\
\mathbf{n}(\%)\end{array}$ & $\begin{array}{c}\text { Group 1, } \\
\mathbf{n}(\%)\end{array}$ & $\begin{array}{c}\text { Group 2, } \\
\mathbf{n ( \% )}\end{array}$ & $\mathbf{p}$ \\
\hline $\mathrm{n}(\%)$ & 300 & $25(8.3)$ & $275(91.7)$ & \\
\hline $\begin{array}{l}\text { Duration of } \\
\text { operation (min) }\end{array}$ & $55.6 \pm 23.5$ & $116.2 \pm 23.4$ & $50.2 \pm 13.7$ & 0.0001 \\
\hline $\begin{array}{l}\text { Calot's dissection } \\
\text { time (min) }\end{array}$ & $14.1 \pm 11.3$ & $33.0 \pm 19.4$ & $12.33 \pm 8.5$ & 0.0001 \\
\hline $\begin{array}{l}\text { Complications } \\
\text { (n) }\end{array}$ & 12 & $9(36)$ & $3(1.1)$ & 0.0001 \\
\hline Min: minute & & & & \\
\hline
\end{tabular}

Min: minute

Table 4. Evaluation of Calot's dissection time with ROC analysis

\begin{tabular}{l}
\begin{tabular}{l|c|c|c|c|c|} 
& $\begin{array}{c}\text { Duration } \\
\text { (min) }\end{array}$ & p & AUC & Sensitivity & Specificity \\
\hline $\begin{array}{l}\text { Calot's } \\
\text { dissection } \\
\text { time }\end{array}$ & $\leq 15$ & 0.0001 & 0.877 & 72 & 84.7 \\
min: minute; AUC: area under curve & & & \\
\end{tabular} \\
\hline
\end{tabular}

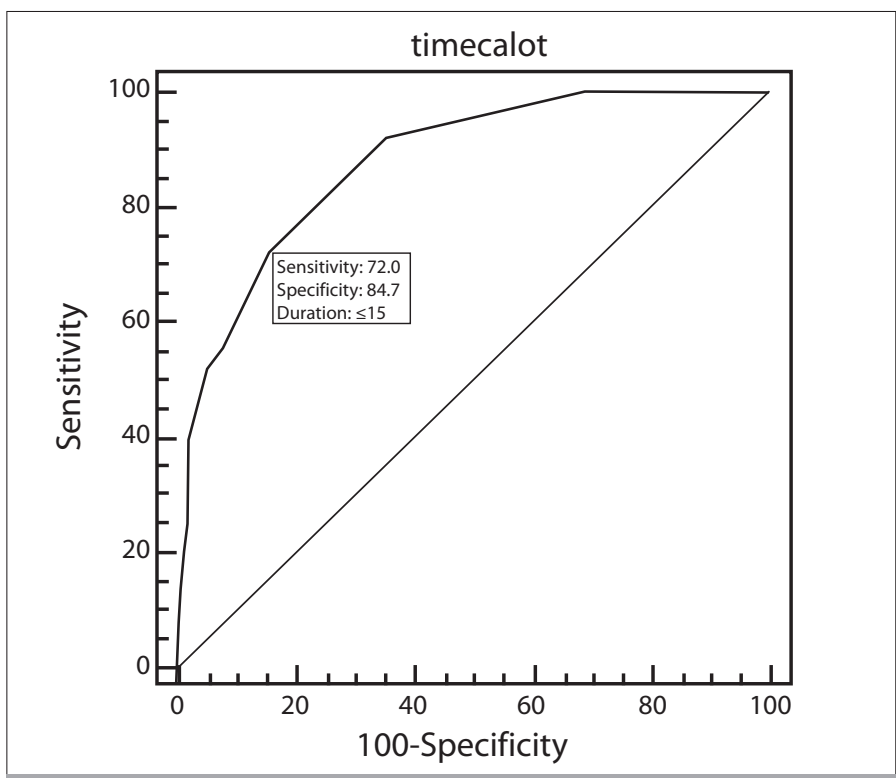

Figure 1. ROC curve for optimum Calot's dissection time 
considered, it is encountered that there are no predictive criteria or scoring systems from laparoscopy to revision or difficult cholecystectomy. There is also no generally accepted definition of difficult cholecystectomy.

Advanced age ( $>50$ years) has been accepted as a significant risk factor for convert to open in many studies (12). In the literature, it is stated that difficult cholecystectomy is expected to increase due to the increase in the frequency of cholecystitis and different operations, especially as age progresses, and Augustine et al. (2) showed no significant relationship between age and difficult pouch because of the similar age group between the groups and the low age values.

Male gender has been defined as an independent risk factor in many studies, but there is no conclusive evidence about the cause (4). This is partly explained by the fact that males have high pain thresholds, less pain, and late pain, as well as fibrogenic predisposition due to differences in hydroxyproline levels $(2,4,17)$. Although not a primary goal in our study, male gender was found to be associated with difficult cholecystectomy, in accordance with previous studies.

Obesity was defined as a risk factor in some studies, whereas it was not significant in some studies (12). In the present study, BMI was not associated with difficult cholecystectomy.

It is believed that a standard cholecystectomy is less likely to be performed in patients with cholelithiasis, as well as choledocholithiasis and acute cholecystitis $(4,12)$. Considering these findings, the accompanying non-cholelithiasis pathologies were considered as exclusion criteria in the study.

In the study by Bourgouin et al. (4), only the operation time was taken into consideration, and the cases that were returned were

Table 5. Complications

\begin{tabular}{|l|c|c|}
\hline Complication & Group 1 & Group 2 \\
\hline Biliary injury & - & - \\
\hline Bilingual leak from a cystic stump & 2 & - \\
\hline Choledocholithiasis & 1 & 1 \\
\hline Hematoma & 2 & 1 \\
\hline Wound infection & 2 & 1 \\
\hline Cardiac complications & 1 & - \\
\hline
\end{tabular}

not included into the difficult cholecystectomy group. Owing to the fact that turning from laparoscopy to a revision was a challenge regardless of the reason, our study included patients who were returned to the open with the duration of surgery, and thus it was thought that the definition of difficulty would be defined with more objective criteria.

Although many preoperative scoring methods have been discussed in the definition of difficult cholecystectomy, scoring methods with operative findings have not been definitely described yet $(14,18)$. It has been argued that difficult cholecystectomy may be due to adhesion and bleeding, abnormal biliary anatomy and fibrosis, or obesity $(2,19)$. In the literature, it is reported that the presence of adhesion in the Calot's triangle increases the risk for difficult cholecystectomy at least threefold $(19,20)$. It is believed that the most objective criterion for determining the degree of difficulty of the Calot's triangle dissection was the time taken to complete the procedure. Within the light of this idea, in this analysis, it was shown that there was a significant relationship between the dissection of the Calot's triangle within $15 \mathrm{~min}$ and the development of difficult cholecystectomy, which is a compatible result with other studies $(4,12)$. Therefore, if this meaningful relationship is proven by prospective studies, it will be possible to accept it as an objective criterion for the definition of difficult cholecystectomy. Although a prospectively recorded database was used in the present study, we believe that the retrospective collection of data is a limitation of our study since all stages of Calot's dissection are not recorded properly.

Laparoscopic cholecystectomy is often selected when starting laparoscopic surgery training; therefore, the estimation of cholecystectomy, which is thought to be difficult, becomes more important in hospitals providing assistant training $(4,20)$. In addition, since there are young and inexperienced surgeons in training hospitals and reference centers, scoring for difficult cholecystectomy will be useful in these hospitals.

Recurrent acute cholecystitis and acute cholangitis episodes were found to be significant risk factors in many studies for difficult cholecystectomy and transition to deficit $(12,21)$. In the present study, there was a significant difference between the groups with and without acute cholecystitis. However, this effect was eliminated in regression analysis, and it was observed that only Calot's triangle dissection time was significant in the model.

It is evident that predicting difficult cholecystectomy will be effective in providing information to the patient about the possibility

Table 6. Multiple regression analysis

\begin{tabular}{l|c|c|c|c|c} 
& \multicolumn{2}{|c|}{ Unstandardized coefficients } & & \multicolumn{2}{c}{ OR (95\% Cl) } \\
\cline { 2 - 5 } & B & Std. Error & P & Lpper \\
\hline Gender & 0.940 & 0.510 & 0.065 & 0.942 \\
\hline Acute cholecystitis & 1.375 & 0.526 & 0.374 & 0.569 \\
\hline Acute cholangitis & 0.087 & 1.146 & 0.230 & 0.419 \\
\hline Calot's dissection $>15$ min & 0.011 & 0.016 & 0.0001 & 1.057 \\
\hline Cl: confidence interval; OR: odds ratio; Std. Error: standard error & & & 1.127 \\
\hline
\end{tabular}


to be exposed to open and organizing the operating room team and program. In the cholecystectomies predicted to be difficult, a more experienced surgical team will perform the operation, the operating room program will be arranged accordingly, the decision will be taken into account prematurely, the intensive use of intensive care beds in patients who may require postoperative intensive care will be considered, and the choice of other minimally invasive LC techniques will be decided by an experienced surgeon. It will provide advantages, such as giving more clear information to the patient about the higher risk of complications (1).

As a limitation of the present study, only if the duration of the Calot's dissection and all the stages of this dissection could be prospectively recorded would it be possible to analyze which stages of the dissection affected the difficulty. Studies that include the objective definition of Calot's dissection and the recording of these periods will contribute to clinical applications by providing objective results.

\section{CONCLUSION}

It can be prevented that the failure to complete the Calot's triangle dissection during a definite period in elective cholecystectomy as a criterion for the development of difficult cholecystectomy may be preventable with regard to other complications.

Ethics Committee Approval: Ethics committee approval was received for this study from the Ethics Committee of Okmeydanı Training and Research Hospital.

Informed Consent: Informed consent was not taken from patients due to the retrospective nature of the study.

Peer-review: Externally peer-reviewed.

Conflict of Interest: The author has no conflict of interest to declare.

Financial Disclosure: The author declared that this study has received no financial support.

\section{REFERENCES}

1. Liu CL, Fan ST, Lai EC, Lo CM, Chu KM. Factors affecting conversion of laparoscopic cholecystectomy to open surgery. Arch Surg 1996; 131: 98-101. [CrossRef]

2. Augustine A, Rao R, Vivek MAM. A comprehensive predictive scoring method for difficult laparoscopic cholecystectomy. J Minim Access Surg 2014; 10: 62. [CrossRef]

3. Chong JU, Lee JH, Yoon YC, Kwon KH, Cho JY, Kim S-J, et al. Influencing factors on postoperative hospital stay after laparoscopic cholecystectomy. Korean J Hepato-Biliary-Pancreatic Surg 2016; 20: 12-6. [CrossRef]

4. Bourgouin S, Mancini J, Monchal T, Calvary R, Bordes J, Balandraud P. How to predict difficult laparoscopic cholecystectomy? Proposal for a simple preoperative scoring system. Am J Surg 2016; 212: 873-81. [CrossRef]
5. Morimoto $Y$, Mizuno $H$, Akamaru $Y$, Yasumasa $K$, Noro $H$, Kono E, et al. Predicting prolonged hospital stay after laparoscopic cholecystectomy. Asian J Endosc Surg 2015; 8: 289-95. [CrossRef]

6. Bingener-Casey J, Richards ML, Strodel WE, Schwesinger WH, Sirinek KR. Reasons for conversion from laparoscopic to open cholecystectomy: a 10-year review. J Gastrointest Surg 2018; 6: 800-5. [CrossRef]

7. Lipman JM, Claridge JA, Haridas M, Martin MD, Yao DC, Grimes KL, et al. Preoperative findings predict conversion from laparoscopic to open cholecystectomy. Surgery 2007; 142: 556-65. [CrossRef]

8. Atmaram DC, Lakshman K. Predictive Factors for Conversion of Laparoscopic Cholecystectomy. Indian J Surg 2011; 73: 423-6. [CrossRef]

9. Ali A, Saeed S, Khawaja R, Samnani SS, Farid FN. Difficulties in Laparoscopic Cholecystectomy: Conversion Versus Surgeon's Failure. J Ayub Med Coll Abbottabad 2016; 28: 669-71.

10. Bat $\bigcirc$. The analysis of 146 patients with difficult laparoscopic cholecystectomy. Int J Clin Exp Med 2015; 8: 16127-31.

11. Rattner DW, Ferguson C, Warshaw AL. Factors associated with successful laparoscopic cholecystectomy for acute cholecystitis. Ann Surg 1993; 217: 233-6. [CrossRef]

12. Gupta N, Ranjan G, Arora MP, Goswami B, Chaudhary P, Kapur A, et al. Validation of a scoring system to predict difficult laparoscopic cholecystectomy. Int J Surg 2013; 11: 1002-6. [CrossRef]

13. Techniques I. Surgical Endoscopy open surgery. 2001; 965-8.

14. Sugrue M, Sahebally SM, Ansaloni L, Zielinski MD. Grading operative findings at laparoscopic cholecystectomy- A new scoring system. World J Emerg Surg 2015; 10: 1-8. [CrossRef]

15. Díaz-Flores A, Cárdenas-Lailson E, Cuendis-Velázquez A, RodríguezParra A, Trejo-Ávila ME. C-Reactive Protein as a Predictor of Difficult Laparoscopic Cholecystectomy in Patients with Acute Calculous Cholecystitis: A Multivariate Analysis. J Laparoendosc Adv Surg Tech 2017; 27: 1263-8. [CrossRef]

16. Joshi MR, Bohara TP, Rupakheti S, Parajuli A, Shrestha DK, Karki D, et al. Pre-operative prediction of difficult laparoscopic cholecystectomy. J Nepal Med Assoc 2015; 53: 221-6. [CrossRef]

17. Akcakaya A, Okan I, Bas G, Sahin G, Sahin M. Does the Difficulty of Laparoscopic Cholecystectomy Differ Between Genders? Indian J Surg 2015; 77: 452-6. [CrossRef]

18. Nassar AHM, Ashkar KA, Mohamed AY, Hafiz AA. Is laparoscopic cholecystectomy possible without video technology? Minim Invasive Ther Allied Technol 1995; 4: 63-5. [CrossRef]

19. Shinde J, Pandit S. Innovative Approach to a Frozen Calot's Triangle During Laparoscopic Cholecystectomy. Indian J Surg 2015; 77: 5547. [CrossRef]

20. Atta HM, Mohamed AA, Sewefy AM, Abdel-Fatah AFS, Mohammed MM, Atiya AM. Difficult Laparoscopic Cholecystectomy and Trainees: Predictors and Results in an Academic Teaching Hospital. Gastroenterol Res Pract 2017; doi: 10.1155/2017/6467814. [CrossRef]

21. Maehira H, Kawasaki M, Itoh A, Ogawa M, Mizumura N, Toyoda S, et al. Prediction of difficult laparoscopic cholecystectomy for acute cholecystitis. J Surg Res 2017; 216: 143-8. [CrossRef] 